\title{
Entre Aristóteles e a fé: Guilherme de Ockham e a determinação da verdade nas proposições sobre o futuro contingente
}

\author{
Carlos Eduardo de Oliveira \\ carloliveira@uol.com.br \\ Universidade Federal de São Carlos, São Carlos, SP, Brasil
}

resumo 0 artigo trata da análise ockhamiana do tema da determinação da verdade nas proposições sobre o futuro contingente, segundo a formulação proposta por Aristóteles em De interpretatione, cap. 9, e de sua relação com o que é proposto sobre este assunto, segundo o próprio 0ckham, "de acordo com a verdade e a fé". A esse respeito, três pontos geralmente são levantados como possíveis decorrências desta leitura de Aristóteles: a assunção de que 0ckham discordaria efetivamente da solução aristotélica, porque errônea; a proposta de que 0ckham tenha claramente vislumbrado na resposta aristotélica a indicação de uma lógica de três valores e, por fim, a recusa ockhamiana da tese da "necessidade do consequiente". Pretendemos mostrar aqui, porém, que apenas o último desses três pontos parece correto.

palavras-chave Guilherme de 0ckham; verdade e falsidade determinadas; futuros contingentes

É pela mão de Boécio, por meio de seus comentários ao De interpretatione de Aristóteles e de sua Consolação da Filosofia, que geralmente se apresenta o debate medieval a respeito do determinismo lógico, segundo a formulação proposta no capítulo nono do $D I^{1}$, que trata da verdade das proposições sobre o futuro contingente. Aparentemente, essa apresentação pode ser resumida em dois pontos. O primeiro deles é a análise da validade do princípio de bivalência quando consideradas as proposições sobre o futuro contingente, tendo em vista as imbricações desta análise com o fatalismo. O outro, a discussão, dita própria do período medieval, sobre as 


\section{8}

implicações da relação entre a determinação da verdade nas proposições sobre o futuro contingente e a eternidade da ciência divina, ou, em outros termos, sobre "a aparente incompatibilidade entre a onisciência divina e a liberdade humana” (cf. STUMP \& KRETZMANN, 1981).

Em várias partes de sua obra, Guilherme de Ockham apresenta sua própria interpretação desta passagem do texto aristotélico e das implicações do que entende estar ali contido quando posto em relação com o que deve ser sustentado "de acordo com a verdade e a fé". A esse respeito, pelo menos três teses são defendidas como possíveis decorrências da leitura ockhamiana de Aristóteles. A primeira sugere que Ockham teria assumidamente discordado da solução aristotélica, que teria considerado errônea. A segunda defende que Ockham teria claramente vislumbrado na resposta aristotélica a indicação de uma lógica de três valores, com a qual estaria em desacordo. A terceira apresenta a recusa de Ockham da tese da "necessidade do conseqüente".

A primeira formulação conjunta destas três teses foi apresentada por Boehner (1945), em resposta a um artigo de Konstanty Michalsky (MICHALSKY, 1937, pp. 233-365). E, seja nos comentários de Boehner, seja em comentários posteriores (por exemplo, CRAIG, 1988; MICHON, 2007), as duas primeiras teses são geralmente apresentadas como entrelaçadas, na medida em que suporiam o mesmo argumento de base: para Ockham, Aristóteles teria negado a bivalência no que diz respeito às proposições que versam sobre o futuro contingente. Tal negação, segundo estes autores, implicaria - de acordo com o que propõem ser a interpretação ockhamiana - que Aristóteles tenha assumido uma lógica trivalente, segundo a qual haveria proposições verdadeiras, falsas e nem verdadeiras nem falsas, ou neutras ${ }^{2}$, a saber, as proposições sobre o futuro contingente.

Para Boehner (1945, p. 67), a questão se reduziria a dizer que Ockham teria considerado a posição aristotélica um erro, não abrindo mão da tese ("não aristotélica") de uma lógica bivalente em favor da tese ("aristotélica”) de uma lógica trivalente. Michon matiza um pouco mais a posição de Boehner, mostrando o exato ponto que distancia as posições de Aristóteles e de Ockham. Se, no que diz respeito às proposições sobre o futuro contingente, Aristóteles teria considerado que seria preciso abrir uma exceção para o princípio de bivalência com o fim de evitar a tese 
fatalista segundo a qual tudo aconteceria necessariamente, frente ao que é proposto pela fé através da presciência divina, Ockham teria considerado a solução aristotélica um passo desnecessário: "o fato de que Ockham tenha depois buscado mostrar como seria possível admitir a presciência sem sucumbir ao argumento fatalista mostra que seu desacordo com Aristóteles é sincero, e não um salvo-conduto.” (MICHON, 2007, p. 13). A novidade da posição ockhamiana seria, então, mostrar que, apesar da argumentação aristotélica, seria possível livrar-se do fatalismo mesmo sustentando uma lógica bivalente, mais compatível com a presciência divina, tal como também propõe Adams (1983; 1987).

Em que pese a opinião de tais comentadores, o ponto de divergência entre a tese que Ockham diz ser a aristotélica e a tese que (na formulação da EPer.) ele diz ser a sustentada "segundo a verdade e os teólogos" parece, porém, ser um pouco mais intricado. Para Ockham, a posição defendida por Aristóteles em DI cap. 9 propõe um problema para a fé: negar que seja possível haver um conhecimento do futuro contingente que não esteja vinculado à determinação daquilo que é futuro contingente e, conseqüentemente, ao fato de que tudo se dê necessariamente (cf. EPer. I, c. 6, S 11 [OCKHAM, 1978, p. 418]). Ockham defende que a fé recusaria a dependência proposta por Aristóteles entre a determinação de algo e a determinação da ciência que se tem disso, ao menos no que diz respeito à ciência de Deus. A principal conclusão tida a partir dá seria a de que, uma vez quebrado este vínculo, a fé teria a faculdade de não precisar conceder a conseqüência necessitarista, escapando, assim, do problema que teria ocupado a Aristóteles. Em suma, para a fé, $<$ a. $>$ o conhecimento da determinação do futuro contingente seria possível para Deus e $<$ b. $>$ esse conhecimento não implicaria que a proposição sobre o futuro contingente fosse também necessária (cf. TP q. 1, Sexta Suposição [OCKHAM, 1978, p. 516, 239-245]). Assim contextualizada a disputa, a bivalência não passaria de um ponto secundário na alegada contraposição entre a fé e Aristóteles. O principal ponto a ser destacado seria, então, o fato de que todo o imbróglio giraria em torno de uma discussão a respeito do modo como Deus conhece.

Para se entender de fato o que é proposto, é preciso examinar com um pouco mais de detalhe a compreensão que Ockham teve da posição aristotélica. Segundo Ockham, em sua Expositio sobre o DI, Aristóteles teria 
defendido que uma proposição sobre o futuro contingente não é nem determinadamente verdadeira nem determinadamente falsa (EPer. I, c. 6, \ 7 [OCKHAM, 1978, p. 414 s.]). Nesse contexto, dizer que uma proposição seja determinadamente verdadeira ou determinadamente falsa implica ao menos duas coisas: que aquilo que é por ela enunciado esteja determinado - isto é, seja de fato tal qual é enunciado - e que, conseqüentemente, tal proposição possa ser conhecida juntamente com seu valor de verdade (cf. EPer. I, cap. 6, \14; TP q. 1, Quinta Suposição [OCKHAM, 1978, p. 421, 2-8; p. 516, 229-238]; BIARD, 1999, p. 97).

Dada esta imbricação, Ockham fala indiferentemente tanto em determinação da verdade de uma proposição quanto em determinação daquilo que é por ela enunciado. $\mathrm{Na}$ sua interpretação do que entende ser a proposta aristotélica, através destas duas expressões Ockham não designa senão que algo de fato seja tal qual é enunciado - para que "Sócrates é branco" seja determinadamente verdadeira, é preciso que Sócrates seja de fato branco agora, semelhantemente, para que "amanhã haverá uma batalha naval" seja agora determinadamente verdadeira, é preciso que haja nas coisas algo que determine a ocorrência futura da batalha naval de modo que sua não realização futura seja agora impossível. Desde este ponto de vista, é possível entender que um paralelo semelhante deveria ocorrer entre o conceito de ciência determinada e a determinação daquilo que é conhecido ( $c f$. Ord. I, d. 38 [OCKHAM, 1979, p. 572, 514. 587, 21-24]), fato que obrigará a Ockham a somar uma espécie de "relativização do tempo" no que diz respeito à determinação da ciência divina, como se verá adiante.

Como vimos, ainda que Aristóteles aponte haver uma relação entre a determinação do que é enunciado (/ da verdade de uma proposição) e a possibilidade de se conhecer esta determinação, a proposta da fé não é senão negar a necessidade desse nexo. Segundo a fé, o conhecimento (/saber: scientia) determinado da verdade da proposição sobre o futuro contingente tido por Deus não requer a determinação do futuro contingente. Em suma, Deus saberia determinadamente qual lado de um par de proposições contraditórias sobre o futuro contingente é verdadeiro. Conseqüentemente, saberia se uma proposição sobre o futuro contingente é verdadeira ou falsa. Mas, ainda assim, a indeterminação do futuro contingente e, conseqüentemente, dos lados da contradição, persistiria: 
sem dúvida se deve assumir que Deus certamente sabe todos os futuros contingentes; de modo que certamente sabe que lado da contradição será verdadeiro e que lado será falso; no entanto, de modo que todas as proposições como "Deus sabe que este - ou aquele - lado da contradição é verdadeiro" são contingentes e não necessárias, tal como já foi dito antes. Mas é dificil ver de que modo o saiba, visto que um lado não está mais determinado para a verdade que o outro. (TP q. 1, Sexta Suposição [OCKHAM, 1978, p. 516, 239-245]. Os grifos são nossos.).

Esse texto do TP parece bem elucidativo do problema enfrentado por Ockham, desde que se tenha em conta a nuance da dificuldade ali apresentada no que diz respeito ao conhecimento divino. Se de um lado o problema é explicar como Deus poderia conhecer como determinado àquilo que na realidade não o é ("visto que um lado não está mais determinado para a verdade que o outro"), de outro lado o problema só se põe ao se assumir como verdadeira a tese de Aristóteles segundo a qual o conhecimento da verdade de uma proposição se segue da determinação da própria proposição, impreterivelmente ligada à determinação daquilo que é por ela enunciado. Note-se, portanto, que a dificuldade não está na posição de Aristóteles, mas em se compreender o que é apontado pela fé dado o que é apresentado pela posição de Aristóteles (cf. Ord. I, d. 38 [OCKHAM, 1979, p. 572, 9-14; p. 584, 3-6. 20-p. 585, 24]).

Diferentemente do que apontam os comentadores citados, frente a esse problema Ockham procurará manter tanto o que é defendido por Aristóteles quanto o que é defendido pela fé. Para isso, a saída encontrada por Ockham passa pela consideração de que, embora Deus saiba determinadamente qual lado da contradição nas proposições sobre o futuro contingente é verdadeiro, este lado seria contingentemente verdadeiro, e, portanto, estaria contingentemente determinado (cf. Ord., loc. cit. [OCKHAM, 1979, p. 587, 21-24]; TP, loc. cit. [OCKHAM, 1978, p. 517, 265-277]), isto é, estaria determinado de modo que seria possível que não fosse determinado e seria possível que jamais tivesse sido determinado:

Se for dito que aquilo que não é verdadeiro em si não pode ser sabido desde outro; ora, eu sentar-me amanhã é deste tipo; digo que é verdadeira, de modo que não falsa, no entanto, é verdadeira 
contingentemente, porque pode ser falsa. (TP, loc. cit. [OCKHAM, 1978, p. 518, 288-291]).

em razão de alguns artistas, cumpre saber que, por mais que Deus saiba sobre todos os futuros contingentes qual lado será verdadeiro e qual falso, esta, no entanto, não é necessária: "Deus sabe que este lado será verdadeiro". Pelo contrário, esta é contingente na medida em que, por mais que "Deus sabe que este lado da contradição será verdadeiro" seja verdadeira, é, no entanto, possível que ela jamais tivesse sido verdadeira. E, neste caso, a potência é para o oposto daquele sem qualquer sucessão, porque é possível que jamais tivesse sido. Ora, não se dá assim com a vontade criada, porque depois que a vontade criada tiver algum ato, não é possível que depois seja verdadeiro dizer que nunca teve tal ato. (cf. Ord. I, d.38 [OCKHAM, 1979, p. 586, 1-11]. O grifo é nosso.).

Portanto, ao contrário do que dizem seus comentadores, mais do que apontar um pretenso erro na filosofia de Aristóteles, a tarefa que Ockham se propõe é a de mostrar em que medida aquilo que é proposto pela fé ainda pode ser visto como algo que não seja contrário à razão. Com efeito, toda a operação ockhamiana gira em torno de negar certa compreensão da tese aristotélica de que não há verdade nem falsidade determinada nas proposições sobre o futuro contingente sem ter de, com isso, negar nem as premissas aristotélicas que levam a essa conclusão, nem aquilo que de fato possa se seguir dessa conclusão. Em seus primeiros contornos, a operação é aparentemente simples: no que diz respeito ao conhecimento que é possível para o homem e à indeterminação da própria coisa futura e contingente, Aristóteles tem razão. Portanto, um lado da contradição não está mais determinado para a verdade que o outro, ou seja, nenhuma proposição sobre o futuro contingente é necessariamente verdadeira nem necessariamente falsa. $\mathrm{O}$ único problema apontado por Ockham na argumentação aristotélica é a generalização que daí se segue. Dada a indeterminação atual do futuro contingente e, conseqüentemente, da verdade ou da falsidade de seu enunciado, Aristóteles defenderia não ser possível que ninguém, Deus inclusive, conheça (obviamente, porque inexistente) a determinação do futuro contingente:

Aristóteles assume que nenhuma proposição contingente que tal sobre o futuro é verdadeira ou falsa, de modo que, segundo a intenção de 
Aristóteles, um lado da contradição em tais não é mais verdadeiro do que o outro. E em razão disto, segundo ele, um lado da contradição não é mais sabido por qualquer que seja o intelecto do que o outro, porque o que não é mais verdadeiro, não é mais sabível. (SL III-3, c. 32 [OCKHAM, 1974, p. 710, 54-59]. O grifo é nosso.)

O nó da solução ockhamiana consiste então em dizer que o conhecimento divino da determinação do futuro contingente, diversamente do que é requerido pela argumentação aristotélica, não se segue da necessidade da verdade da proposição, ou seja, da determinação atual daquilo que é por ela enunciado. Portanto, tal como vimos, Ockham ainda parece sustentar, junto com o que crê ser a opinião de Aristóteles, que uma proposição apenas seria necessariamente verdadeira se aquilo que ela enuncia estivesse necessariamente determinado, isto é, se fosse ou tivesse sido tal como é enunciado no presente ou no passado ou se não pudesse ser de modo diferente daquele que é enunciado através da proposição sobre o futuro. Ora, de um lado, o problema é que Aristóteles não considera que o futuro contingente seja determinado deste modo; de outro, e o que é mais importante, segue-se do que é sustentado por Ockham que nem Deus o conheceria como determinado deste modo. De acordo com a posição que Ockham defende ser a proposta "segundo a verdade e a fé", Deus conhece a verdade do futuro contingente como contingentemente determinada. Ou seja, Ockham propõe que onde até então, segundo o cânone aristotélico, apenas se falava em verdade necessária, com base no que propõe a fé, seja considerada a existência de uma verdade contingente.

A questão, então, é explicar o que exatamente isso quer dizer, uma vez que, desde a perspectiva que Ockham propõe ser a aristotélica, tal afirmação de que há um conhecimento (scientia) de uma verdade "contingentemente determinada" pode parecer nada mais que um completo absurdo: a afirmação de que algo esteja determinado e a de que seja possível conhecer (/saber) tal determinação parece, desde a perspectiva "aristotélico-ockhamiana", incompatível com o que o próprio Ockham propõe ser a contingência da verdade. Afinal, nessa acepção, uma proposição é contingentemente verdadeira ou contingentemente determinada não porque é verdadeira mas poderia ter sido falsa 


\section{4}

(o que seria, então, algo análogo à "necessidade condicionada" proposta por Boécio, da qual se falará adiante). Uma proposição é contingentemente verdadeira (/determinada) porque é verdadeira e pode ser falsa (TP q. 1, Sexta Suposição, loc. cit.). Ora, desde o ponto de vista que Ockham defende ser o aristotélico, exatamente porque Sócrates poderia não ter se sentado, só é possível se saber (/conhecer, scire) que a proposição "Sócrates está sentado" é verdadeira porque Sócrates de fato assim o está. Deste modo, porque já não é mais possível que Sócrates não tenha se sentado, é necessário que o tenha feito. Em outras palavras, ainda que trate de um evento contingente, não é possível que a proposição: "Sócrates está sentado" não seja verdadeira agora, portanto, é necessário que seja verdadeira e apenas por isso pode ser conhecida como determinada deste modo. Portanto, na perspectiva que Ockham entende ser a aristotélica, não haveria lugar para tal proposição contingentemente verdadeira. Afinal, são coisas diversas que uma proposição trate do que é contingente e que a proposição seja necessariamente verdadeira ou falsa: uma proposição é necessariamente verdadeira ou falsa apenas porque aquilo que é por ela enunciado é (ou não) tal como é enunciado, trate ela do que é necessário ou do que é contingente.

O problema ganha ainda maior importância quando percebemos que a tese da existência de uma verdade contingente claramente afasta Ockham de uma interpretação sobre o conhecimento divino dos futuros contingentes que seja semelhante àquela que se afirma ser a interpretação "tradicional" ou boeciano-tomasiana (que MARENBON, 2005, questiona se seria de fato a interpretação de Boécio ou de Tomás de Aquino) a respeito do conhecimento divino do futuro contingente, segundo a qual Deus conheceria a tudo, seja presente, passado ou futuro, num presente eterno, e, portanto, conheceria aquilo que para nós é o futuro contingente, assim como o que para nós é presente ou passado, como atemporalmente presentes para si: na formulação de Duns Escoto - que certamente foi conhecida por Ockham (cf. Ord. I, d. 38 [OCKHAM, 1979, p. 585, 15-20]) -, " "que tudo fosse presente para Deus na eternidade segundo a sua existência atual" ou "que todo o fluxo do tempo e tudo que há no tempo seja presente para a eternidade" (DSLect. I, d. 39, q. 5 [DUNS ESCOTO, 1966, p. 486, 3 s.]; DSOrd. I, d. 38, pars II et d. 39, q. 1-5 [DUNS ESCOTO, 1963, p. 407, 20 s.]) $)^{3}$. 
O ponto exato da divergência desta interpretação com a tese ockhamiana é o fato de que tal leitura permitiria dizer que Deus conhece o futuro contingente como necessariamente determinado, e, portanto, como necessariamente verdadeiro, o que não implica, como apontamos, que aquilo que é conhecido deixe de ser em si mesmo contingente. Nesta interpretação, o conhecimento do futuro contingente estaria submetido ao princípio de necessidade condicionada, assim como formulado por Boécio, também conhecido nas interpretações contemporâneas como princípio de necessidade acidental ou temporal ou do presente:

Ora, visto que o conhecimento divino é imóvel e conhece qualquer coisa como presente, seus objetos são de todos os modos necessários, com uma necessidade que é aquela do presente segundo a doutrina aristotélica, e - Tomás o explicou no corpo do artigo - esta necessidade não impede que os acontecimentos assim previstos, que são para nós futuros, sejam contingentes. (MARENBON, 2005, p. 143).

A solução dada por Ockham consiste, portanto, em afirmar que, apesar de Deus conhecer a determinação do futuro contingente, ele não a conhece de um modo que possa submeter o que é conhecido ao princípio da necessidade acidental. O ponto é que Ockham parece compreender que a tese do conhecimento divino de algo como presente estaria vinculada à tese aristotélica de que a determinação real de algo é concomitante à determinação da verdade da proposição que o enuncia. Afinal, só parece haver sentido em se considerar que Deus conhece o futuro como algo presente para si se com isso for admitida a tese de que o conhecimento da determinação de algo se segue da determinação real de algo: Deus conhece que $a$ será porque vê presentemente para si que $a$ ét. O grande problema que leva Ockham a rejeitar a tese do conhecimento divino do que é futuro como algo presente para si parece ser o de que aceitar tal tese seria de algum modo equivalente ou a aceitar a tese de que o temporal seja a causa do eterno ${ }^{5}$, o que ele não admite como possível (cf. Ord. I, d. 41 [OCKHAM, 1979, p. 610, 7 s.]), ou a aceitar a tese de que o conhecimento divino seria a causa efetiva total ou parcial do evento contingente.

A desvinculação que Ockham parece propor entre o conhecimento divino e a tese aristotélica de que o conhecimento da determinação da 


\section{6}

proposição parte da determinação da própria coisa aparece como fundamental para que se compreenda inclusive a dificuldade que Ockham encontra naquilo que é proposto pela fé. Afinal, o próprio Ockham reconhece que, apesar do que é apresentado pela revelação a respeito do conhecimento divino do futuro contingente, é impossível conceber racionalmente como Deus conhece os futuros contingentes:

digo para a questão que sem dúvida se deve ter que Deus sabe certa e evidentemente todos os futuros contingentes. Mas declarar isto evidentemente e exprimir o modo pelo qual sabe todos os futuros contingentes é impossivel a todo intelecto em seu estado atual. [...]

No entanto, não obstando esta razão [sc. a afirmação de Aristóteles de que o que não é verdadeiro em si, não pode ser sabido naquele tempo em que não é verdadeiro em si], deve-se ter que Deus conhece evidentemente todo futuro contingente. Mas não sei o modo de exprimi-lo. No entanto, pode ser dito que o próprio Deus, ou a essência divina, é uma cognição intuitiva, tanto de si mesmo quanto de todos os outros factíveis e não factíveis, tão perfeita e tão clara que ela também é notícia evidente de todos os passados, futuros e presentes. De modo que, assim como a partir de nossa notícia intuitiva intelectiva dos extremos, o nosso intelecto pode conhecer evidentemente algumas proposições contingentes, assim a própria essência divina é certa cognição e notícia pela qual não se sabe unicamente o verdadeiro, o necessário e o contingente sobre o presente, mas também é sabido qual lado da contradição será verdadeiro e qual será falso. E isto talvez não se dê em razão da determinação de sua vontade. Mas, também, posto por impossível que a própria cognição divina existindo tão perfeita assim como é neste instante, não seria a causa efetiva nem total nem parcial dos efeitos contingentes, ainda assim seria a notícia pela qual seria evidentemente sabido por Deus qual lado da contradição será falso e qual será verdadeiro. E isto não se daria porque os futuros contingentes seriam presentes para ele, nem através de idéias como se através de razões de conhecer, mas através da própria essência divina ou cognição divina, que é a notícia pela qual se sabe o que é falso e o que é verdadeiro, o que foi falso e o que foi verdadeiro, o que será falso e o que será verdadeiro. (Ord. I, d. 38 [OCKHAM, 1979, p. 583, 21-584, 2. 20-585, 20]. Os grifos são nossos). 
Toda a dificuldade, então, estaria em explicar como seria possível para Deus conhecer como determinado àquilo que, presentemente, está absolutamente indeterminado porque futuro. Mais precisamente: como Deus pode conhecer como verdadeiro aquilo que está absolutamente indeterminado porque absolutamente dependente de uma vontade livre. Desde logo é possível perceber que o problema aqui levantado pelas teses de Ockham parece muito mais geral que a questão dos futuros contingentes, pois consiste em explicar como Deus conhece qualquer coisa além de si que se dê de modo contingente, tendo como ponto de partida tanto o princípio de que o temporal não é causa do eterno como o princípio de que o conhecimento divino também não é causa do temporal contingente, já que a cognição divina "não seria a causa efetiva nem total nem parcial dos efeitos contingentes". Em suma, dada a contingência, a tese de que Deus "conhece tudo através de sua essência" (cf. Ord. I, d. 35, q. 5 [OCKHAM, 1979, p. 479-507]) parece encontrar o seu limite: não ser capaz de prover, segundo a interpretação ockhamiana, uma explicação racionalmente compreensível para o homem em seu estado atual do conhecimento divino do contingente, seja ele passado, presente ou futuro.

Portanto, na sua contraposição a Aristóteles, aparentemente a fé não faz senão negar a validade de uma tese aristotélica à primeira vista bastante razoável e que parece ter sido adotada sem restrições - ao menos no que diz respeito ao conhecimento possível para o homem "no estado da vida atual" - pelo próprio Ockham: a tese da verdade como correspondência.

Como vimos, seguindo o que entende ser a posição aristotélica, Ockham propõe que uma proposição não é verdadeira senão quando há certa correspondência entre o que é enunciado e um estado de coisas, ou, segundo seu próprio vocabulário, quando uma voz é (ou não) predicada a outra não por si mesma, mas em virtude da coisa (cf. EPer. I, cap. 2, $\mathbb{} 1$ [OCKHAM, 1978, p. 383 s., lin. 30-42]):

deve-se notar que a verdade e a falsidade da proposição não são certas qualidades inerentes à própria proposição daquele modo pelo qual a brancura inere à parede, porque, sem nenhuma mudança por parte da proposição, em razão unicamente da mudança por parte da coisa, a mesma proposição pode primeiramente ser verdadeira e depois falsa, assim 
como 'Sócrates senta-se', ele sentado, é verdadeira, e depois, levantando-se ele, sem qualquer mudança por parte da proposição, é falsa. Ora, a verdade e a falsidade são certos predicáveis da proposição, que importam que tal qual é por parte do significado, assim é denotado pela proposição que é o signo; donde, a proposição ser verdadeira não é a proposição ter alguma tal qualidade em si, mas a proposição ser verdadeira é ser tal qual é significado pela proposição. Donde, se Sócrates se senta, então 'Sócrates senta-se' é verdadeira, porque é tal qual é denotado pela proposição 'Sócrates senta-se'; e se Sócrates não se senta, então 'Sócrates senta-se' é falsa, porque não é tal qual é denotado por 'Sócrates senta-se'; e deve-se dizer do mesmo modo sobre todos os outros, como se dirá à frente. (EPer. I, Proêmio, $\mathbb{S} 12$ [OCKHAM, 1978, p. 376, 92-107]).

Sendo assim, dizer que uma proposição é determinadamente verdadeira não é senão afirmar que tal correspondência existe de fato e que, portanto, pode ser conhecida (/sabida). Desse modo, inicialmente não parece realmente haver diferença em se dizer, sem mais, que uma proposição é determinadamente verdadeira ou que uma proposição é verdadeira (cf. BOEHNER, 1945, p. 48 ou SL III-3, cap. 32, em que Ockham usa simplesmente "verdade" numa discussão que em outros textos fala de "verdade determinada"). A dúvida é saber se o conceito de verdade e de "verdade determinada" mantêm uma relação congruente entre si.

Há pelo menos um argumento a favor de que estes conceitos exprimam coisas diversas: o fato de toda oração enunciativa ser declarada por Ockham ou verdadeira ou falsa. Segundo Ockham, Aristóteles teria apresentado assim a oração enunciativa, principal objeto de sua consideração no DI: "nem toda oração é enunciativa, mas apenas aquela que é verdadeira ou falsa" (EPer., cap. 4, \$1 [OCKHAM, 1978, p. 391, lin. 13 s.]). Ora, se dizer que uma proposição não seja nem verdadeira nem falsa for de qualquer modo equivalente a dizer que uma proposição não seja nem verdadeira nem falsa determinadamente, rigorosamente a pretensa enunciação sobre o futuro contingente não seria sequer uma enunciação ${ }^{6}$ (Problema semelhante parece ser vislumbrado no que diz respeito à interpretação da posição do próprio Aristóteles em BARBOSA FILHO, 2005, p. 174 s.). O próprio Ockham, no entanto, jamais traçou qualquer consideração a respeito desta dificuldade, o que leva a crer que não parece 
possível afirmar com certeza que Ockham tenha de fato admitido que Aristóteles teria aberto mão do princípio de bivalência no que diz respeito às proposições sobre o futuro contingente: ao contrário do que já se afirmou (MICHON, 2007, p. 43, n. 2), a consideração ockhamiana de uma verdade determinada, tal como aparentemente o é em Boécio (cf. BARBOSA FILHO, 2003), pode ser a via de saída de Ockham da interpretação sobre a verdade das proposições sobre o futuro contingente chamada de "tradicional".

Mas ainda que se verifique que, ao contrário do que acabamos de sugerir, não seja o caso de que uma possível exceção concedida por Aristóteles para o princípio de bivalência anularia o status de enunciação da proposição sobre o futuro contingente, tampouco parece correto o juízo que afirma que a noção ockhamiana de verdade determinada não acrescentaria senão confusão à noção de verdade da proposição (cf. MICHON, loc. cit.): ao falar que as proposições sobre o futuro contingente não são nem determinadamente verdadeiras nem determinadamente falsas, Ockham não estaria senão ressaltando a característica que falta para a atribuição da verdade ou da falsidade para as proposições sobre o futuro contingente, a saber, a determinação daquilo que é por elas enunciado e a conseqüente impossibilidade de conhecer como determinado àquilo que é indeterminado. Em outras palavras, Ockham estaria reclamando aqui a tese de que a realidade é a causa do enunciado, veritas sequitur esse rerum, que em seu próprio vocabulário não seria senão a tese de que as palavras são signos das coisas (cf. SL I, 1 [OCKHAM, 1974, p. 7 ss.]):

segundo a intenção do Filósofo, não apenas nas futuras contingentes, pelo contrário, também naquelas proposições sobre o presente e o passado que equivalem às sobre o futuro, Deus não sabe mais um lado da contradição que o outro, pelo contrário, nenhum dos dois, segundo ele, é sabido por Deus, uma vez que, segundo ele, Segundos Analíticos I, não se sabe senão o verdadeiro. Ora, não há verdade determinada naquelas porque, segundo ele, não pode ser imputada nenhuma razão pela qual um lado seja mais verdadeiro que o outro, e assim, ou ambos serão verdadeiros ou nenhum; ora, não é possível que ambos sejam verdadeiros; logo, nenhum, e, portanto, nenhum é sabido. (TP q. 1, Quinta Suposição [OCKHAM, 1978, p. 516, 229-238]. Os grifos são nossos.). 
E, tal como em Boécio (cf. BARBOSA FILHO, 2003, p. 189), o impedimento aqui não é meramente epistêmico: a impossibilidade de se tomar uma proposição como determinadamente verdadeira não deriva da impossibilidade de se saber o que é por ela enunciado, tal qual um náufrago, numa ilha deserta, ficaria impossibilitado de saber o que se passa no continente. No caso dos futuros contingentes, essa impossibilidade deriva do fato de que aquilo que é contingente não está mais determinado a ser do que a não ser, uma vez que depende da ação de um agente livre. Assim, é porque o futuro contingente não está mais determinado a ser do que a não ser que ele não pode ser sabido. Portanto, o problema que o Filósofo traz para a fé não é, de fato, a negação da bivalência, mas aquilo que, exista ou não tal negação, necessariamente a precede: a afirmação da não determinação do futuro contingente e, conseqüentemente, da impossibilidade de seu conhecimento.

Diante deste quadro, Ockham apresenta o que é proposto pela fé não como a negação da tese aristotélica, mas como uma formulação complementar (mas não contrária) a alguns de seus pontos. Para a fé, a proposição que enuncia o futuro contingente não é nem determinadamente verdadeira nem determinadamente falsa de modo não contingente, ou seja, ela é contingentemente determinadamente verdadeira ou contingentemente determinadamente falsa. Portanto, ainda que num sentido bem preciso, a interpretação que Ockham crê ser a aristotélica permanece impecável: a fé propõe uma diferença entre a determinação (necessária) do que é enunciado por uma proposição (que, na interpretação de Ockham, parece ser a única considerada por Aristóteles) e sua determinação contingente, ao propor que seja diferente a verdade necessária e a verdade contingente de uma proposição.

Em suma, para a fé, assim como o próprio futuro contingente não está determinado na realidade de modo a haver nele uma potência real para o oposto sem qualquer sucessão (cf. Ord. I, d. 38, em texto supracitado), a proposição sobre o futuro contingente está determinada de modo contingente e, portanto, é verdadeira contingentemente, enquanto a proposição sobre o passado ou o presente, ou mesmo sobre o futuro necessário, está determinada necessariamente e, portanto, é necessariamente verdadeira.

A base da tese ockhamiana de que há tanto uma determinação (/verdade) necessária como uma determinação (/verdade) contingente 
não é outra que a tese da necessidade do passado. Mas Ockham tira proveito da distinção segundo a qual apesar de as proposições verdadeiras sobre o presente, o passado ou o futuro necessários serem absolutamente necessárias (necessariae simpliciter), as proposições verdadeiras sobre o presente e o passado contingentes são apenas acidentalmente necessárias (per accidens, na expressão cunhada provavelmente por Guilherme de Sherwood, equivalente à "necessidade condicionada" de Boécio): “[...] O que digo em razão das proposições necessárias por acidente, tais quais são muitas proposições sobre o passado. E são necessárias por acidente porque foi contingente que fossem necessárias, nem sempre foram necessárias." (Ord. I, Prol., q. 6 [OCKHAM, 1967, p. 178, 4-7]. O grifo é nosso.). Ora, é apenas ao se diferenciar da interpretação que apresentamos acima como sendo a da "atemporalidade" do conhecimento divino, que a interpretação ockhamiana pode tornar compreensível a consideração de uma verdade contingente, na medida em que afirma que apenas está sujeito à necessidade acidental aquilo que está realmente determinado com relação ao tempo presente. Ou seja, para Ockham, apenas o que é temporalmente (e não atemporalmente ou epistemicamente) presente pode de algum modo ser submetido à regra de que "toda proposição verdadeira sobre o presente tem alguma necessária sobre o passado" (Quodl. IV, q. 4 [OCKHAM, 1980, p. 315, 22 s.]):

[...] segundo o Filósofo, em Ética VI [c. 2, 1139 b 10-11]: “Deus está privado apenas disto: tornar não gerado aquilo que foi feito". Isto deve ser entendido assim: se alguma proposição puramente sobre a inerência, e sobre o presente, e que não seja equivalente a uma sobre o futuro, for verdadeira neste momento, de tal modo que seja verdadeira sobre o presente, ela sempre será verdadeira sobre o passado; porque se a proposição "esta coisa é" for verdadeira neste momento, qualquer que seja a coisa mostrada, "esta coisa foi" sempre será verdadeira depois; e nem Deus, por sua potência absoluta, pode fazer com que essa proposição seja falsa. (TP q. 1 [OCKHAM, 1978, p. 507 s., 16-23]. O grifo é nosso.).

Fica, portanto, evidente que o problema tratado por Ockham a partir do que é proposto pela fé, isto é, a partir da proposta da determinação da verdade da proposição sobre o futuro contingente em vista do conhecimento divino é na verdade apresentar como a tese da determinação 
contingente de uma verdade pode coexistir com a tese de sua determinação necessária. E é apenas graças ao aspecto "relativo ao tempo" que Ockham propõe ao conhecimento divino que será possível estabelecer a diferença da determinação e, conseqüentemente, da verdade contingente do futuro contingente, da verdade necessária do contingente presente ou passado (necessariamente) determinado. De fato, é somente neste ponto que aparecerá com clareza a novidade daquilo que Ockham propõe ser a posição da fé quanto à interpretação aristotélica. Para Aristóteles, o futuro contingente seria algo que, "em si", não estaria mais determinado para ser do que para não ser:

E digo que o Filósofo diria que Deus não sabe evidente e certamente nenhum futuro contingente. E isto por esta razão: porque aquilo que não é verdadeiro em si, não pode ser sabido naquele tempo em que não é verdadeiro em si. Ora, o futuro contingente, que depende absolutamente de uma potência livre, não é verdadeiro em si. Porque não pode, segundo ele, ser atribuída a razão pela qual um lado é mais verdadeiro do que o outro, e, assim, ou cada um dos lados é verdadeiro ou nenhum. E não é possível que cada um dos lados seja verdadeiro, portanto, nenhum é verdadeiro, e, conseqüentemente, nenhum é sabido. (Ord. I, d. 38, q. única [OCKHAM, 1979, p. 584, 3-11]. Os grifos são nossos.).

“Temporalizando" a afirmação aristotélica de que o contingente futuro não seja verdadeiro em si, Ockham fará com que seja possível conciliar o que pretende Aristóteles com aquilo que afirma a fé, assim: dado o que é afirmado pela fé, isto é, que Deus conhece a determinação do futuro contingente, parece ser perfeitamente possível dizer que o futuro contingente seja algo verdadeiro em si:

Em quarto lugar, o que não é verdadeiro em si, não é sabido por Deus por notícia determinada; ora, o futuro contingente é deste modo;

portanto, etc. [...]

Quanto ao quarto, é patente que a menor é falsa. No entanto, [o lado da contradição] é verdadeiro de modo que é contingentemente verdadeiro, porque pode ser falso, e poderia jamais ter sido verdadeiro. (TP, q. 2, art. 1 [OCKHAM, 1978, p. 520, 16 s.; 521, 39 ss.]. O grifo é nosso. A esse mesmo respeito, veja-se também: Ord. I, d. 38

[OCKHAM, 1979, p. 572, 5-14. 587, 21-24]). 
Mesmo assim, a fé não proporia nada em contrário ao que defende Aristóteles, porque ele estaria correto ao defender que o futuro contingente seria algo que não é verdadeiro (nem falso) em si e que não pode ser sabido naquele tempo em que não é verdadeiro em si. Ou seja, assim como o compreendeu Aristóteles, no presente, o futuro contingente ainda não é verdadeiro em si. Deus, porém, ainda que conheça o futuro contingente como algo de fato futuro, o conhece - de um modo que não nos é possível compreender - tal qual ele será, isto é, como verdadeiro em si, uma vez que seu conhecimento não pode ser tomado como causa daquilo que é futuro. E enquanto algo futuro contingente, isto é, algo que ainda não se realizou, há para o futuro contingente uma potência real, sem qualquer sucessão, para que ele seja de um modo diverso daquele pelo qual Deus o conhece, daí a formulação ockhamiana de que algo seja contingentemente determinado "de modo que ainda é possível não ser determinado, e é possível que jamais tivesse sido determinado" (TP q. 1, Sexta Suposição [OCKHAM, 1978, p. 517, 265 ss.]).

Aqui cabe, por fim, uma observação: se, diferentemente do que vimos já ter sido defendido, Ockham não parece verdadeiramente considerar a existência de algum erro na solução aristotélica, a tentativa de aproximação entre o que Ockham sustenta ser afirmado pela fé e a filosofia de Aristóteles tampouco deve ser vista como uma tentativa de salvar a Aristóteles. Pelo contrário. A aproximação proposta por Ockham não passa da tentativa de fazer daquilo que é defendido pela fé algo que não seja completamente contrário à razão: na perspectiva ockhamiana, apesar de a compreensão do modo como Deus conhece ser algo inatingível para o homem, a tese da existência de uma verdade contingente tampouco contradiz aquilo que é possível para o homem conceber racionalmente. Aquilo que Aristóteles defende como indeterminado dado o modo pelo qual o homem é capaz de conceber as coisas, só é defendido como determinado pela fé segundo o modo de conhecer divino que, apesar de inacessível ao intelecto humano, não é contraditório com o que ele pode conhecer, na medida em que a questão é reapresentada pela fé propondo novos significados para os conceitos nela envolvidos.

E porque, embora necessário (cf. TP q. 2 [OCKHAM, 1978, p. 520 532]), o conhecimento divino do futuro contingente não implica senão uma verdade contingente, novamente diversamente do que defende, por 
exemplo, Tomás de Aquino (cf. MICHON, 2004, p. 62; ST I, q. 14, a. 13, ad $2 \mathrm{~m}$ ), Ockham pode negar haver a transferência da necessidade do saber divino para aquilo que é conhecido por ele. Em outras palavras, tal como defende Boehner (1945) na terceira das teses que apresentamos logo no início desse texto, Ockham nega a tese da necessidade do conseqüente (cf. QVar. q 3 [OCKHAM, 1984, p. 87-92]):

tudo que é sabido por Deus que há de ser, necessariamente será; $a$ é sabido por Deus que há de ser; então a necessariamente será. A maior é sobre o necessário, porque o predicado inere ao sujeito necessariamente; e a menor é sobre a inerência absolutamente, porque é verdadeira na eternidade; portanto, se segue a conclusão sobre o necessário. Digo que a maior é falsa, porque exprime o sentido da divisão, $e$ muitos que hão de ser sabidos por Deus serão contingentemente e não necessariamente, e, por isso, se segue a conclusão falsa. Mas se a maior for tomada no sentido da composição, de modo que "tudo sabido por Deus [que há de ser] será” seja necessária, então a junção não vale, porque a menor é sobre a inerência quanto ao agora, e, por isso, não se segue a conclusão. (TP, q. 2, a. 4 [OCKHAM, 1978, p. 532, 329-338]. O grifo é nosso.).

Neste ponto, porém, mais importante que saber por quais argumentos Ockham nega que seja logicamente válida a transferência da necessidade do saber divino para aquilo que é conhecido por ele - a saber, basicamente pela consideração dos tipos de inerência e do modo pelo qual se dá a indução nas proposições sobre a inerência (cf. SL III-3, cap. 32 [OCKHAM, 1974, p. 708-714.]) -, parece ser compreender como Ockham entende que a possibilidade de tal transferência chega a ser vislumbrada. Adams, por exemplo, a cuja exposição parecem seguir a maioria dos comentários contemporâneos sobre a solução ockhamiana para a querela dos futuros contingentes, parece considerar que o principal problema visado por Ockham na interpretação da teoria aristotélica fosse o da tese da necessidade do passado:

Dada esta alegada especificação aristotélica das condições de verdade, se todas as proposições singulares tivessem o valor de verdade determinado desde a eternidade, então não haveria nem nunca teria havido quaisquer futuros contingentes, mas tudo que se torna passado 
foi necessitado desde a eternidade por algo determinado e atualizado no passado. (ADAMS, 1987, p. 1139).

Com base nisto, Adams chega até mesmo a propor que o principal argumento aristotélico segundo o qual ele supostamente teria aberto mão da bivalência quanto às proposições sobre o futuro contingente seria surpreendentemente falacioso:

O raciocínio [sc. assumido por Aristóteles como válido] aqui é surpreendentemente falacioso: se tudo se torna passado necessariamente, não só seríamos determinados por algo passado para agirmos como agimos, mas deveríamos inclusive ser determinados a deliberar como deliberamos, e se nossas deliberações guardam certa relação com nossas ações, isto provavelmente se daria porque elas foram necessitadas a ser assim por algo real ou atual no passado. (ADAMS, 1987, p. 1140).

A conclusão, no entanto, não parece encontrar respaldo na leitura ockhamiana da proposta aristotélica. Primeiro porque mistura dois momentos diversos da argumentação do texto aristotélico na leitura ockhamiana desta argumentação. $\mathrm{Na}$ interpretação ockhamiana, a aplicação da tese da necessidade da verdade das proposições sobre o passado ao que é enunciado pelas proposições sobre o futuro contingente não parece ser para Aristóteles mais do que uma das conseqüências da assunção de que a verdade sobre o futuro contingente estaria desde sempre determinada. O problema, tal qual o expõe Ockham e já falamos aqui, é que a consideração de que as proposições sobre o futuro estejam determinadas não implica, mas pressupõe o fato de que as coisas que serão futuras estejam determinadas, o que, de acordo com a argumentação aristotélica, não parece possível porque isto implicaria que não há espaço para qualquer deliberação: "nada se daria por acaso ou quanto ao que se queira, mas tudo se daria por necessidade" (EPer. I, cap. 6, \7 [OCKHAM, 1978, p. 415, 27 s.]). Não seria senão como uma conseqüência do fato de que todas as coisas estão desde sempre determinadas que as orações passadas seriam necessariamente verdadeiras.

Com efeito, Ockham diz que Aristóteles teria sustentado que não há verdade nem falsidade determinadas nas proposições sobre o futuro 
contingente através de duas razões que só justificam essa tese porque mostram por que seria um erro sustentar a opinião contrária. A primeira é a que acabamos de enunciar: dizer que as orações sobre o futuro contingente estejam determinadas implica pressupor que as coisas futuras estejam determinadas:

E prova isto conduzindo ao impossível, assim: se toda proposição afirmativa e negativa for determinadamente verdadeira ou determinadamente falsa, então, se alguém disser: 'isto será', e outro disser: 'isto não será', é preciso que um deles diga determinadamente o verdadeiro, se qualquer que seja a proposição for determinadamente verdadeira ou determinadamente falsa, assim como se alguém disser: 'isto será branco', e outro disser: 'isto não será branco', é preciso que um diga determinadamente o verdadeiro e que o outro determinadamente minta. Ora, isto é falso, porque então nada se daria por acaso ou quanto ao que se queira, mas tudo se daria por necessidade. Esta última conseqüência é patente, porque aquilo que é quanto ao que se queira não é mais determinado para um lado que para o outro, isto é, não é mais determinado a ser que a não ser. Portanto, se é determinado que será ou que não será, não se dá quanto ao que se queira, mas por necessidade. (EPer. I, cap. 6, $\mathbb{\$} 7$ [OCKHAM, 1978, p. 415, 20-32]).

A segunda razão traz à baila a tese da necessidade do passado: Aqui põe a segunda razão, que é que se isto for presentemente branco, e se há verdade determinada naquelas sobre o futuro, então 'isto será branco' foi antes verdadeira; melhor: 'isto será branco' sempre foi verdadeira. Ora, se o futuro sempre foi, então o futuro não pôde não ser, portanto, não pôde não se dar, portanto, foi impossível que não se desse, portanto, foi necessário que se desse; e assim por diante. E, conseqüentemente, tudo se dá por necessidade, e nada se dá por acaso nem quanto ao que se queira. E esta razão fundamenta-se nisto que é proposto: que a proposição singular verdadeira sobre o passado é necessária. Portanto, se 'esta foi verdadeira: isto será branco' for presentemente verdadeira, ela é necessária, e, conseqüentemente, é necessário que se dê e não pode acontecer algo diferente. (EPer. I, cap. 6, $₫ 8$ [OCKHAM, 1978, p. 415 s., 2-12]). 
Embora um pouco mais intrincada, a apresentação desta segunda razão não parece fazer mais do que mostrar as conseqüências da negação da tese de que a verdade da enunciação pressupõe a determinação da coisa enunciada. Em outras palavras, a segunda razão não indica senão que dizer que as orações sobre o futuro contingente estejam determinadas implica assumir em algum momento que a determinação da verdade da proposição não pressupõe a determinação da coisa. $\mathrm{O}$ argumento é o seguinte: Isto é branco agora. Se há verdade determinada naquelas sobre o futuro, então: "esta foi verdadeira: isto será branco". Ora, toda proposição verdadeira sobre o passado é necessariamente verdadeira. Portanto, foi necessário que o futuro se desse e nada se dá por acaso ou quanto ao que se queira.

Aqui é preciso notar a ressalva proposta por Ockham já no início do argumento: a conclusão só é válida se for concedido que há verdade determinada nas proposições sobre o futuro contingente. A tese da necessidade do passado não é posta, portanto, em função de permitir a conclusão de que há verdade determinada nas proposições sobre o futuro contingente. A tese da necessidade do passado permite apenas a conclusão (no mais, redundante) de que tudo se dará por necessidade. O importante a ser notado aqui, portanto, é que a tese de que há verdade determinada nas proposições sobre o futuro contingente não é uma conclusão do raciocínio exposto, mas é uma das premissas, o que não parece, porém, ser suficiente para fazer com que o argumento deixe de ser circular. Em todo caso, se a tese de que há verdade determinada nas proposições sobre o futuro for tomada como válida, uma proposição que tal há de ser verdadeira antes mesmo que haja a própria determinação presente da coisa enunciada. Ou seja, o argumento é exclusivamente formal: assumida sem mais, tal tese inicialmente não faz senão dissociar a determinação da verdade da proposição da determinação atual da coisa que é por ela enunciada, argumento que é fundamental para a elaboração da primeira razão. E uma vez abolida esta relação, embora não seja mais possível dizer por que uma proposição sobre o futuro seja determinadamente verdadeira senão por uma referência à bivalência (a enunciação tem de ser ou verdadeira ou falsa), exatamente porque ela foi afastada de seu compromisso inicial com a realidade, é possível dizer que ela sempre foi determinadamente verdadeira, e que, conseqüentemente, cai sob a tese de 
que a proposição singular verdadeira sobre o passado é necessária. Afinal, em qualquer momento do tempo, seja ele anterior à determinação presente da coisa enunciada pela proposição futura, seja ele posterior a tal determinação, será verdadeiro enunciar: "esta foi verdadeira: isto será branco”. Daí a conclusão de que tudo se dá por necessidade e nada se dá por acaso nem quanto ao que se queira: a verdade da proposição em vez de supor, implicaria a determinação da coisa.

Em nenhum momento, portanto, parece correto dizer, como sugere Adams, que todo o problema da interpretação aristotélica gira em torno de que as coisas estejam determinadas por algo passado. Afinal, o problema de base das duas razões apresentadas não parece ser senão o choque entre dois princípios com os quais a tese da necessidade do passado não é senão concorrente: a consideração de que todas as coisas estejam determinadas e a negação de que haja deliberação, princípio que pode ser tomado como evidente por $\mathrm{si}^{7}$. Deste modo, o papel da tese da necessidade do passado parece sempre propositadamente posto em segundo plano. Afinal, na primeira razão ela simplesmente não é posta em jogo, mesmo que eventualmente se mostre que ela seja a única capaz de tornar crível a tese de que todas as coisas estejam determinadas (mas, então, tratar-se-ia de uma das possíveis reconstruções do argumento Dominador, que não é considerado aqui. Cf., por exemplo, VUILLEMIN, 1984). Ali, o argumento se limita a mostrar que a tese da determinação da verdade de todas as proposições, independentemente do modo pelo qual possa ser sustentada, implica uma improvável conseqüência ontológica (todas as coisas estão determinadas independentemente da deliberação). Na segunda, em que a tese da necessidade do passado exerce papel efetivo, a determinação de todas as coisas apenas é tomada como a conseqüência da tese da necessidade do passado quando aliada à anulação do pressuposto de que a determinação da verdade da proposição depende da determinação da própria coisa (anulação, aliás, que desabona sua credibilidade), numa argumentação que serve mais uma vez para dar destaque não a outra coisa que a tensão anunciada: a negação da deliberação.

Assim, na interpretação de Ockham, a força do absurdo denunciado por Aristóteles não consiste em afirmar que até mesmo nossas deliberações estariam determinadas por um evento passado, mas em afirmar que as coisas aconteceriam ainda que à revelia de nossas deliberações: 
Nesta parte o Filósofo infere muitas inconveniências do inconveniente inferido, dizendo que esta inconveniência e outras que tais são as que se seguem se for concedido que tanto nas universais quanto nas singulares seja necessário que um lado da contradição seja verdadeiro e o outro falso, porque, assim, nada se daria quanto ao que se queira, mas tudo se daria por necessidade. Além do que se segue que não é preciso nem que se delibere nem que se negocie, porque do que está determinado, deliberemos ou não, se dá assim como foi determinado no princípio. E não vale dizer que não é verdadeiro dizer que isto será unicamente quanto ao futuro próximo, não sobre o remoto; porque nada acrescenta dizer se acaso é verdadeiro dizer que 'isto será' agora ou com mil anos de antecedência. Nem vale dizer que alguém que diga 'isto será' ou 'isto não será' diz o falso em razão do que diz, porque não é em razão do afirmar ou do negar de alguém que a oração é verdadeira ou falsa, mas disto que é por parte da coisa tal qual é significada, ou que não é tal qual é significada. E desse modo nada acrescenta dizer 'isto é verdadeiro: isto será' com mil anos de antecedência ou depois. E, por isso, se for determinadamente verdadeiro que isto será ou não será, tudo se dá por necessidade e nada se dá por acaso nem quanto ao que se queira. (EPer. I, cap. 6, \ 11 [OCKHAM, 1978, p. 418]. Os grifos são nossos.).

De fato, ainda que visualize as implicações ontológicas da questão, Adams parece considerar que todo o problema enfrentado por Aristóteles não ultrapassa os limites de sua formulação lógica, uma vez que Aristóteles somente teria sido levado a abrir mão da bivalência para evitar as conseqüências da tese da necessidade do passado:

Por outro lado, se algo vem a ser ou veio a ser alguma vez passado contingentemente - no sentido que antes que ele viesse a ser ele não estava nem determinado a vir a ser nem determinado a não vir a ser então nem toda proposição singular tem um valor de verdade determinado desde a eternidade.

Na leitura medieval, a escolha de Aristóteles se deu sem hesitação: ele insistiu na contingência futura para preservar a liberdade da ação humana e a eficácia da deliberação. Aparentemente, ele pensou que se tudo se tornasse passado necessariamente,

... não haveria necessidade de deliberar ou conciliar, desde que do fato 
de que está determinado [se segue] que irá acontecer como está determinado desde o início, deliberemos ou não. (ADAMS, 1987, p. 1139 s. O grifo é nosso.).

Assim apresentada a questão, não é de admirar que se encontre uma falácia aí. Mas também importante é a implicação que essa leitura impõe à interpretação daquilo que é próprio à "solução" que teria sido proposta pelo pensamento ockhamiano a esse impasse. Todo o problema da determinação da verdade das proposições sobre o futuro contingente se reduzindo à imposição derivada da tese da necessidade do passado, o trabalho de Ockham não poderia ser senão descobrir um modo de contornar tal imposição. E Ockham o teria feito mostrando algo óbvio: a tese da necessidade lógica do passado só vale quando se considera que a determinação da verdade de uma proposição apenas tem lugar quando é definida por algo real ou atual no passado ou no presente relativo ao tempo enunciado pela proposição: "portanto, se " $p$ é verdadeiro' é verdadeiro (falso) agora, ' $p$ foi verdadeiro' será necessário (impossível) em qualquer tempo posterior" (ADAMS, 1987, p. 1142). Sua "solução" seria, então, propor que a verdade (falsidade) determinada de uma proposição num tempo anterior ao do que é enunciado pela proposição deve ser definida pelo que é real ou atual em um tempo qualquer (at some time or other):

'x é (foi, será) $A$ em $t m$ ' é determinadamente verdadeiro em $t n$, se, e somente se, em um tempo qualquer, não há (houve, haverá) nenhuma potência nas coisas para que $x$ não seja (tenha sido, venha a ser) $A \mathrm{em} \mathrm{tm}$ e

'x é (foi, será) $A$ em tm' é determinadamente falso em $t n$, se, e somente se, em um tempo qualquer, não há (houve, haverá) nenhuma potência nas coisas para que $x$ seja (tenha sido, venha a ser) $A$ em $\operatorname{tm}[\ldots]$

Se, por exemplo, 'Pedro negará Cristo em tm' for determinadamente verdadeira desde a eternidade, deve ser o caso de que há uma potência para que Pedro não o negue em todos os tempos anteriores a tm. Em tais casos, a proposição é verdadeira de modo que ela pode ser falsa e pode nunca ter sido verdadeira, dado que nada real ou atual exclui a potência para o oposto. Conseqüentemente, a verdade determinada passada de tais proposições não cai sob a necessidade do passado. 
Ockham torna esta conseqüência explícita na seguinte passagem: [seguese a citação de TP q. 1, Terceira Suposição.] (ADAMS, 1987, p. 1141 s.).

Trocando em miúdos a formulação proposta, parece que se seguiria o seguinte: " $x$ será $A$ amanhã" é determinadamente verdadeira hoje, se, e somente se, não houver nada que possa impedir que $x$ seja $A$ amanhã. Ora, a formulação apresentada não faz mais do que tentar retratar que $A$ pode ser ou um evento necessário simpliciter, ou um evento necessário per accidens, isto é, um evento que, ainda que contingente, não se dará mais de outro modo em virtude da determinação de um ato da vontade. No limite, a formulação não expressaria mais do que dizer: " $x$ será amanhã" é determinadamente verdadeira hoje, se, e somente se, $x$ for $A$ amanhã. Restaria, então, perguntar em que sentido esta formulação resolveria o problema principal do argumento ockhamiano, a saber, que só é possível dizer que uma proposição futura contingente é determinadamente verdadeira antes que o evento enunciado se realize porque Deus sabe a verdade da proposição. Poder-se-ia perguntar até mesmo em que sentido a formulação resolveria o problema da formulação aristotélica: que não há verdade nem falsidade determinada nas proposições sobre o futuro contingente porque nenhum dos lados da contradição está mais determinado para a verdade do que o outro antes que a vontade exerça seu papel.

Além disso, o trecho citado da Terceira Suposição para justificar o argumento de Adams, isto é, a possível solução de Ockham frente à opinião aristotélica, não o justifica, afinal o argumento que é ali empregado por Ockham para livrar as proposições futuras contingentes da necessidade do passado é exatamente o mesmo de Aristóteles: não há nenhuma determinação real atual nas coisas que permita tomar como necessariamente verdadeira uma proposição qualquer sobre o futuro contingente, afinal, somente uma proposição verdadeira sobre o presente segundo a $\operatorname{voz} e$ segundo a coisa tem alguma proposição verdadeira necessária sobre o passado (cf. TP q. 1 e ibidem, Terceira Suposição [OCKHAM, 1978, p. 507 s., 432 .p. 515, 208-212]). Assim, a célebre solução ockhamiana segundo a qual uma proposição como "Pedro é predestinado", que é sobre o presente segundo a voz, mas não segundo a coisa, "não cai sob a necessidade do passado porque equivale a uma proposição sobre o futuro" não é mais do que a aplicação strictu sensu do argumento aristotélico que acabamos de 
mencionar. O que vai além do argumento aristotélico é a afirmação de que, ainda assim, tal proposição seria, no entanto, verdadeira porque depende da verdade de proposições sobre o futuro. (ibidem, p. 515, 212-216). Mas, então, voltamos a falar da verdade contingente conhecida por Deus.

Assim, não parece possível aceitar que ofereça qualquer solução para o problema a tese de Adams segundo a qual enquanto a solução aristotélica abre uma lacuna (gap) para os valores de verdade quando os futuros contingentes são considerados, a solução por ela apresentada como sendo a de Ockham, baseada na superação da tese da necessidade do passado, teria fechado esta lacuna e restaurado a lei do terceiro excluído:

E se é sempre o caso de que um ou outro lado da contradição referente ao futuro contingente é determinadamente verdadeiro e, portanto, cognoscível, a presciência universal de Deus pode ser preservada. (ADAMS, 1987, p. 1141).

Afinal, não se vê como tal "solução" ajude a sustentar a presciência divina se, como afirma com razão a própria autora, a indicação proposta por Ockham de que Deus conheceria os futuros contingentes através de uma notícia intuitiva perfeitíssima não é suficiente sequer para superar a dificuldade de "se é possível, quer lógica, quer metafisicamente, que Deus tenha tal conhecimento" do futuro contingente (cf.ADAMS, 1987, 1147).

Desse modo, parece evidente que Ockham não pretende senão propor a tese aristotélica da indeterminação atual do futuro contingente e a tese "da fé e dos teólogos" de sua determinação contingente como perfeitamente conciliáveis. Sem discordar verdadeiramente em momento nenhum do que entende ser a opinião de Aristóteles, todo o esforço ockhamiano parece ser o de mostrar o quanto seriam compatíveis a fé e a filosofia aristotélica, mostrando que, na maioria das vezes em que esse não parece ser o caso, não se daria senão que ambas não tratariam exatamente das mesmas coisas sob os mesmos termos. De fato, para Aristóteles, o futuro contingente não é verdadeiro em si no presente, para a fé, ele o é no futuro. Para Aristóteles, o futuro contingente não é (necessariamente) determinado, para a fé, ele é contingentemente determinado dado o conhecimento divino. Do mesmo modo, parece ser possível dizer que, na interpretação de Ockham, Aristóteles teria entendido que, no presente, a proposição sobre o futuro contingente não seria nem determinadamente 
verdadeira nem determinadamente falsa de modo necessário - assim como o é também para a fé, que afirma, no entanto, que ainda assim ela seria contingentemente determinadamente verdadeira ou falsa dado o conhecimento divino. Rigorosamente, a filosofia aristotélica e a fé apenas estariam em desacordo, portanto, na afirmação aristotélica de que ninguém poderia conhecer a verdade do futuro contingente, que a fé afirma ser contingentemente conhecida por Deus de modo a não se sujeitar a qualquer tipo de necessidade antes de sua realização atual. Mas nem desta vez parece possível se falar propriamente em um erro do estagirita, ignorante da revelação.

Em suma: para Ockham, a argumentação aristotélica a respeito da determinação da verdade das proposições sobre o futuro contingente parece perfeita no que diz respeito ao conhecimento possível para o intelecto humano em seu estado atual. Portanto, Aristóteles teria razão em tudo, menos na sua negação do conhecimento divino dos futuros contingentes. Mas é exatamente porque Aristóteles teria razão em seus argumentos que é impossível explicar como Deus conhece o futuro contingente...

1 Uma tábua com as abreviações adotadas é apresentada no final do artigo.

2 Em BOEHNER, 1945, p. 82 s., há a indicação de que também Walter Burley teria visualizado a possibi-lidade de se entender a tese aristotélica como defensora de uma lógica de três valores, ainda que Burley provavelmente hesitasse conceder que essa de fato tenha sido a posição aristotélica. Em MICHON, 2007, p. 12, aparece a indicação de que esta mesma tese teria sido defendida antes mesmo de Ockham por Pedro Auréolo, que, diferentemente de Burley, a teria assumido como se a própria posição de Aristóteles.

3 Conforme MARENBON, 2005, p. 125: "Conforme a tese realista, nada é, na realidade, passado ou futuro com relação a Deus, pois existe entre a eternidade divina e o tempo uma relação tal que a eternidade e não importa qual instante do tempo são simultâneos. Deus compreende então que toda coisa é presente para si porque, com relação a si mesmo, toda coisa é, na realidade, presente (Os exegetas de Boécio apresentam uma versão desta tese que eu chamei 'a interpretação realista atemporal', em que esta relação se funda sobre a atemporalidade de Deus; mas nela mesma, a tese realista não exige, ao menos teoricamente, que Deus seja atemporal, e eu diferencio no $₫ 5$ a consideração do estatuto temporal ou atemporal de Deus no Aquinate.). Pelo contrário, segundo a tese epistêmica, não se pretende que aquilo que está no futuro ou no passado não seja futuro ou passado com relação a Deus. Deus simplesmente tem a capacidade de conhecer os acontecimentos que são futuros como se eles fossem presentes: conhecendo-os assim, ele não os conhece como eles são neles mesmos." (Os grifos são do autor, os sublinhados são nossos.)

doispontos, Curitiba, São Carlos, vol. 7, n. 1, p.137-169, abril, 2010 
4 De acordo com Marenbon (2005, p. 125-139) é Joseph de Finance (1956, "La présence des choses à l'étérnité d'après les scolastiques", Archives de Philosophie 19, p. 24-62.) quem apresenta a mais importante análise moderna do pensamento de Tomás de Aquino a respeito do conhecimento divino do futuro contingente, segundo a qual Tomás assumiria uma solução realista (equivalente à interpretação atemporal) em vez de uma solução epistêmica. Acrescente-se a isso que De Finance teria também o suporte de quase toda a tradição tomista, do comentário sobre as sentenças de João Chabrol (c. 1380-1444) aos to-mistas do século vinte, além do suporte dos críticos desta tradição, como João Duns Escoto. Em suma, segundo o resumo apresentado por Marenbon, para De Finance é possível entender de duas maneiras bem diferentes que todas as coisas estejam presentes para Deus: $<$ a. $>$ segundo a interpretação objetiva (equivalente à tese epistêmica): "o futuro é presente para Deus porque, desde agora, o seu olhar, que transpassa os séculos como o nosso transpassa o espaço, o contempla com a mesma acuidade e certeza da que se ele já estivesse lá"; <b. $>$ segundo a interpretação realista: "se Deus, eternamente, vê as coisas, isto se dá porque, independentemente, por assim dizer, de sua visão, elas estão, eternamente, diante dele." (cf. MA-RENBON, 2005, p. 126).

5 Crítica semelhante já havia sido levantada à teoria tomasiana por Duns Escoto, em DSOrd. I, d. 38, pars II et d. 39, q. 1-5 (DUNS ESCOTO, 1963, p. 411): "Em segundo lugar, porque o intelecto divino não recebe nenhuma certeza de algum objeto diverso de sua essência, pois, assim, envileceria. Donde mesmo agora o intelecto divino não tem certeza de minha ação que está posta em ato de modo que esta ação desde si cause a certeza no intelecto divino; com efeito, ela não move aquele intelecto. Portanto, do mesmo modo, tudo que é temporal - se estiver em sua existência presente à eternidade segundo a existência proposta por aqueles - não produz no intelecto divino a certeza sobre si, mas é preciso que tenha uma notícia certa do que é existente através de algo diverso do temporal, e tal algo diverso é o que basta para nós."

${ }^{6}$ Como se sabe, parte da tarefa dos comentários medievais ao DI é explicar os vários tipos de oração. Dizer que uma oração não seja uma enunciação, parece implicar que ela pertença ou a outro gênero de oração ou, então, que aquilo que nos parece inicialmente ser uma oração de fato não o seja: "Ora, que nem toda oração seja enunciativa é patente, porque a oração deprecativa é uma oração e nem é verdadeira nem falsa, e, conseqüentemente, não é enunciativa." (EPer. I, cap. 4, \ 1 [OCKHAM, 1978, p. 391, lin. 14-16]. O grifo é nosso.). Boécio assim explica essa classificação: a oração é um gênero dividido inicialmente entre orações perfeitas e imperfeitas. Uma oração imperfeita não diz nada, ou melhor, não resulta numa sentença $(s c$. "sententiam non expedit"), como "Platão no Liceu". Uma oração perfeita, por sua vez, é completa e tem como resultado uma sentença. Em seu Comentário Maior, Boécio dá como exemplos de espécies de orações perfeitas a oração deprecativa, isto é, de súplica, a oração imperativa, a interrogativa (substituída pela optativa em seu Comentário Menor), a vocativa e a enunciativa (BOÉCIO, 1877, p. 70 ss.; 1880, p. 95 s. / 1990, 313 D; 442 A). Ockham, em lista semelhante, também lembra alguns destes tipos de oração: "a oração divide-se em indicativa, imperativa, optativa, etc.” (EPer. I, cap. 3, \$ 4 [OCKHAM, 1978, p. 390, 15 s.]).

Em sua exposição, Tomás de Aquino estabelece uma ordem para esses tipos de oração. Inicialmente, assim como Boécio em seu Comentário Maior, diz que há cinco espécies de orações perfeitas: a enunciativa, a deprecativa, a imperativa a interrogativa e a vocativa (Exp.Per. I, 1. 7, n. 4). Explica em seguida que as orações enunciativas destinam-se a dizer o verdadeiro e o falso, enquanto significam os próprios conceitos da mente. Os outros tipos de oração também 
significam certa ordem da razão, mas de acordo com aquilo a que são destinados: primeiro, a oração vocativa, para que se preste atenção à mente, em segundo lugar, a oração interrogativa, para que se responda à voz, em terceiro, no que toca ao executar ordens, a oração imperativa para aquilo que é inferior e a oração deprecativa para o que é superior. Tomás aponta ainda que a oração optativa é reduzida à oração deprecativa: o homem não tem como mover o que lhe é superior senão por meio da expressão de seus desejos. Por fim, diz ainda que as orações enunciativas dividem-se em indicativas e supositivas, do que temos o seguinte esquema: as orações perfeitas dividem-se em cinco espécies, a saber, enunciativa, vocativa, interrogativa, imperativa e deprecativa. A essas espécies são reduzidas ainda outras formas de oração. Pertencem à enunciação as orações indicativas e supositivas. São reduzidas às orações interrogativas as orações dubitativas, assim como as optativas às deprecativas (cf. Exp.Per. I, 1. 7, n. 5).

7 É Duns Escoto que denuncia que a contingência não é algo que possa ser provado nem através de algo mais conhecido (notius) nem de algo a priori, mas é conhecida por si: "Em razão de que deve ser tomado como conhecido por si que há contingência nos entes, - e quem nega isso carece de sentido e pena; e por isso Avicena ensina em sua Metafísica que hão de ser expostos ao fogo os que negam o que é manifesto aos sentidos, já que para eles é o mesmo ser queimados ou não ser queimados. Donde o Filósofo, argumentando contra aqueles que dizem que tudo acontece necessariamente, leva-os não ao que é mais impossível, mas a alguns que são mais conhecidos em nossos atos: que, assim, 'não seria preciso nem deliberar nem conciliar'." (DSLect. I, d. 39, q. 1-5 [DUNS ESCOTO, 1966, p. 491, 17-24]); “Donde o Filósofo, argumentando contra a necessidade daqueles que são futuros, não deduz a algo hipoteticamente impossí-vel, mas a algo impossível a nós mais manifesto, a saber, que não é preciso nem deliberar nem conciliar. E por isso os que negam tais manifestos carecem de pena ou sentido, porque - segundo Avicena em Metafísica I - aqueles que negam o primeiro princípio devem ser açoitados ou expostos ao fogo, até que concedam que não é o mesmo ser queimado e não ser queimado, ser açoitado e não ser açoitado. Do mesmo modo estes que negam algum ente 'contingente' devem ser expostos a tormentos, até que concedam que é possível não os torturar." (DSOrd. I, d. 38 pars 2 et d. 39, q. 1-5, Appendix $A$ [DUNS ESCOTO, 1963, p. 415, 6-14]).

\section{Abreviações dos trabalhos citados}

das obras de Guilherme de Ockham

EPer. Expositio in Librum Perihermenias Aristotelis;

SL Summa Logicae;

TP Tractatus de Praedestinatione et de Praescientia Dei Respectu Futurorum

Contingentium.

Ord. Scriptum in Librum Primum Sententiarum (Ordinatio);

Quodl. Quodlibeta Septem;

QVar. Quaestiones Variae. 
das obras de outros autores

Aristóteles

DI De interpretatione.

Tomás de Aquino

Exp.Per. In Aristotelis Libros Peri Hermenias Expositio;

ST Summa Theologiae.

João Duns Escoto

DSOrd. Ordinatio, Liber Primus (Opus Oxoniense);

DSLect Lectura in Librum Primum Sententiarum.

\section{Referências bibliográficas}

ADAMS, M. MC., 1983. Introduction. In: GUILHERME DE OCKHAM, 1983, p. 1-33. 1987. William Ockham :Volume II. Notre-Dame:

Notre-Dame UP.

ARISTOTELES. 1936. Organon: I. Catégories; II. De l'interprétation. Tradução e notas de J. Tricot. Paris:Vrin. 1995. The Complete Works of Aristotle. Transl. by J. L.

Ackrill. The Revised Oxford Translation. Edited by J. Barnes. Princeton: UP, $6^{a}$ edição, volume I.

BARBOSA FILHO, B., 2003. Nota sobre a Contingência: Boécio, Comentador de Aristóteles. In: WRIGLEY, M. B. \& SMITH, P. (org.), O filósofo e sua história: uma homenagem a Oswaldo Porchat. Campinas: Unicamp, Centro de Lógica, Epistemologia e História da Ciência, p. 183-197. . 2003b. Nota sobre o Conceito Aristotélico de Verdade. Cadernos de História e Filosofia da Ciência, Campinas, Série 3, Vol. 13 (2), p. 233-244. 2005. Aristóteles e o Princípio de Bivalência. Analytica, Rio de Janeiro, Vol. 9 (1), p. 173-184. 
BIARD, J., 1999. Guillaume d'Ockham et la théologie. Paris: Cerf.

BOÉCIO 1877. Anicii Manlii Severini Boetii Commentarii In Librum Aristotelis Peri Hermeneias: Pars Prior.Versionem Continuam et Primam Editionem Continens. Leipzig: Teubner. 1880. Anicii Manlii Severini Boetii Commentarii In Librum Aristotelis Peri Hermeneias: Pars Posterior. Secundam Editionem et Indices Continens. Leipzig: Teubner. 1990 [1891]. Manlii Severini Boetii Opera Omnia: In Librum Aristotelis de Interpretatione Libri Duo. Editio Prima, Seu Minora Commentaria \& In Librum Aristotelis de Interpretatione Libri Sex. Editio Secunda Seu Majora Commentaria. MIGNE, Patrologia Latinae, 64. Turnhout: Brepols, cc. 293-640.

BOEHNER, PH., 1945. Problems connected with the Tractatus: Ockham and the Problem of a three-valued Logic. In: Idem, The Tractatus de Praedestinatione et de Praescientia Dei et de Futuris Contingentibus of William Ockham: with a Study on the Mediaeval Problem of a Three-valued Logic. Nova Iorque:The Franciscan Institute, p. 43-88.

CRAIG, W. L., 1988. The Problem of Divine Foreknowledge and Future Contingents from Aristotle to Suarez. Leiden: Brill.

GUILHERME DE OCKHAM. 1974. Opera Philosophica:Vol. I Summa Logicae. Nova Iorque: St. Bonaventure University. .1978. Opera Philosophica:Vol. II Expositionis in Libros Artis Logicae Proemium, et, Expositio in Librum Porphyrii de Praedicabilibus. Expositio in Librum Praedicamentorum Aristotelis. Expositio in Librum Perihermenias Aristotelis. Tractatus de Praedestinatione et de Praescientia Dei Respectu Futurorum Contingentium. Nova Iorque: St. Bonaventure University. 1967. Opera Theologica:Vol. I -

Scriptum in Librum Primum Sententiarum (Ordinatio). (Prologus et Distinctio Prima). Nova Iorque: St. Bonaventure University. 
.1979. Opera Theologica:Vol. IV -

Scriptum in Librum Primum Sententiarum (Ordinatio). (Dist. XIXXLVIII). Nova Iorque: St. Bonaventure University.

1984. Opera Theologica:Vol.VIII -

Quaestiones Variae. Nova Iorque: St. Bonaventure University. .1980. Opera Theologica:Vol. IX -

Quodlibeta Septem. Nova Iorque: St. Bonaventure University. 1945. The Tractatus de

Praedestinatione et de Praescientia Dei et de Futuris Contingentibus. In: BOEHNER, Ph., The Tractatus de Praedestinatione et de Praescientia Dei et de Futuris Contingentibus of William Ockham: with a Study on the Mediaeval Problem of a Three-valued Logic. Nova Iorque: The Franciscan Institute, p. 1-40. 1983. Predestination, God's

Foreknowledge and Future Contingents. Translated, with introduction, notes and appendices, by Marilyn McCord Adams and Norman Kretzmann. $2^{a}$ edição. Indianápolis: Hackett. .2007, Traité sur la prédestination. Textes introduits, traduits et annotés par Cyrille Michon. Paris:Vrin. JOÃO DUNS ESCOTO. 1963. Opera Omnia, vol. VI: Ordinatio. Liber Primus a Distinctione Vigesima Sexta ad Quadragesimam Octavam. Civitas Vaticana: Typis Polyglottis Vaticanis. 1966. Opera Omnia, vol. XVII: Lectura in

Librum Primum Sententiarum a Distinctione Octava ad Quadragesimam Quintam. Civitas Vaticana: Typis Polyglottis Vaticanis.

LOPES DOS SANTOS, L. H., 1998. Leibniz e os futuros contingentes. Analytica, Rio de Janeiro, Vol. 3 (1), p. 91-121.

MARENBON, J., 2005. Le temps, l'éternité et la prescience de Boèce à Thomas d'Aquin. Paris:Vrin.

MICHALSKY, Konstanty. 1937. "Le problème de la volonté à Oxford et à Paris au XIVe siècle”. Studia Philosophica. Lemberg, 
MICHON, C., 2004. Prescience et liberté: essai de théologie philosophique sur la Providence. Paris: PUF. 2007. Introduction: Prédestination, Prescience et Futurs Contingents. In: GUILHERME DE OCKHAM, 2007, p. 7-71.

STUMP, E. \& KRETZMANN, N., 1981. Eternity. The Journal of Philosophy.Vol. LXXVIII, n. 8, p. 429-458.

TOMÁS DE AQUINO. 1955. In Aristotelis Libros Peri Hermenias et Posteriorum Analyticorum Expositio. Cum textu ex recensione leonina. Cura et studio R. M. Spiazzi. Torino: Marietti.

1962. Summa theologiae. Roma: Editiones

Paulinae.

VUILLEMIN, J., 1984. Nécessité ou contingence: l'aporie de Diodore et les systèmes philosophiques. Paris : Minuit. 